\title{
The Effect of Age and Anthropometric and Somatic Variables on Agility Performance in Adolescent Ice Hockey Players
}

\author{
Lukáš Ondra, Zdeněk Svoboda \\ Faculty of Physical Culture, Palacký University Olomouc
}

\begin{abstract}
Agility, one of the components that affect performance, is beneficial in invasion sports, such as ice hockey. This study aimed to assess the relationship between agility and pubescence in adolescent male ice hockey players. Agility and anthropometric and somatic data were evaluated in 60 male participants (age, $12.98 \pm 1.44$ years). Participants were divided into 5 groups according to age from 11 to 15 years (11y to 15y). Anthropometric and somatic variables were observed using a bioelectrical impedance device. Agility performance level was evaluated by T-Test and Edgren Side Step Test (EDGREN). Significance level was set at $p \leq 0.05$. One-way analysis of variance was used to investigate mean differences. A significant effect of age was found for height, body weight, and skeletal muscle mass percentage. Tukey's (HSD) post hoc test revealed significant differences in height and body weight between all age groups. The T-Test revealed significant differences between all groups, except between groups $11 y$ and $12 y, 12 y$ and $13 y$, and $14 y$ and $15 y$. EDGREN showed differences only between groups $11 y$ and $13 y$ and $11 y$ and $15 y$. Significant Pearson correlations were found between all monitored variables and both agility tasks. Agility improves with age in adolescent male ice hockey players. In ice hockey, EDGREN is suitable for testing agility skills in children from the end of middle childhood to early adolescence because it is less influenced by anthropometric and somatic variables. The T-Test should be used in testing agility in late adolescent and adult hockey players when maturation is completed.
\end{abstract}

Keywords: maturation, body composition, Edgren Side Step Test, T-Test, youth

\section{INTRODUCTION}

Ice hockey is a complex sport that requires the contribution of many different physical and psychological components for success at the elite level (Burr et al., 2008). Agility, one of the components that affect performance, is beneficial in invasion sports, such as ice hockey. A high level of agility performance is advantageous to attackers to evade their opponent's tackles and to defenders to reduce space on the field to limit attacking movements or achieve a turnover (W. B. Young, Dawson, \& Henry, 2015). During skating, on-ice agility is a major component of ice hockey (Bracko, Fellingham, Hall, Fisher, \& Cryer, 1998). Skating in ice hockey is a complex skill involving the contributions of many diverse components. The ability to generate power during a stride will provide a more meaningful contribution to skating speed if the player exerts the force while being well balanced and stable (Behm, Wahl, Button, Power, \& Anderson, 2005).

Agility is considered as a key part of performance in team sports (Paul, Gabbett, \& Nassis, 2016). Chelladurai defined the forms of agility performance as simple, temporal, spatial and universal (Chelladurai, 1976). This division provide a unique framework for the understanding of the demands of many sports (Sheppard \& Young, 2006). Nowadays, although the common definition of agility is inconsistent (Sheppard, Dawes, Jeffreys, Spiteri, \& Nimphius, 2014) the term agility is broadly defined by Sheppard and Young (Sheppard \& Young, 2006) as "a rapid whole-body 
movement with change of velocity or direction in response to a stimulus" (p. 922). According to the authors (Sheppard \& Young, 2006) this definition "respects the cognitive components of visual scanning and decision making that contribute to agility performance in sport" (p. 922). The definition was adopted by other authors (Jeffreys, 2011; Scanlon, Humphries, Tucker, \& Dalbo, 2014; W. Young \& Rogers, 2014). However, the new deterministic model of agility (W. B. Young et al., 2015) indicates the main factors (i.e. cognitive, physical and technical), that determine agility in invasion sports such as ice hockey, basketball etc., differs from the previous one (W. B. Young, James, \& Montgomery, 2002), by excluding change of direction speed (CODS). The stimulus to change velocity or direction is typically the actions of opponents, in terms of that, change of direction speed is not a component of agility, but a different skill (W. B. Young et al., 2015).

The time of agility performance decreases during pubescence in childhood up to maturity with the highest decrease from 7 to 10 years (27.1\%) and from 10 to 14 years (26.5\%) of age and with the lowest decrease from 14 to 18 years of age (16.5\%) (Zemková \& Hamar, 2012). However, agility skills may be influenced by participation in organized sports in childhood and adolescence (Zemková \& Hamar, 2014). Considering ice hockey, the on-ice training is more effective in the development of agility performance, however training off-ice agility provides a sufficient motor transfer to on-ice agility performance (Novák, Lipinska, Roczniok, Spieszny, \& Stastny, 2019). The level of motor development, influenced also by agility skills level, is determined by somatic traits, such as body height and subcutaneous fat tissue, in childhood and adolescence. These determinants primarily affect speed and strength abilities of children aged 8-years 12 than their older counterparts aged 13-16 years (Puciato, Mynarski, Rozpara, Borysiuk, \& Szyguła, 2011). Overweight and obesity in children aged 13-18.5 years is associated with lower performance in speed-agility tasks compared to subjects with normal weight (Artero et al., 2010).

To reach the elite level in ice hockey, it is also necessary to meet the current basic physical parameters such as body height and weight. These values indicate the current level of optimal development of basic physical parameters that predict a possible success, taking into account various game positions (Sigmund, Kohn, \& Sigmundova, 2016). High-level Canadian players aged $13.1 \pm 0.6$ years were characterized by higher values of height and weight compared to the reference population with the same age (Allisse, Sercia, Comtois, \& Leone, 2017). Moreover, young Russian hockey players aged 13-16 years tend to have higher body weight compared to inactive peers (Surina-Marysheva, Erlikh, Korableva, Kantyukov, \& Ermolaeva, 2018). With respect to physiological profile, there are some differences among various positions, and the physiological profile of elite players has changed over the past decades (Quinney et al., 2008).

Although agility is an important factor in ice hockey, the association between off-ice agility testing and anthropometric and somatic variables, such as height, weight, skeletal muscle mass (SMM), fat-free mass (FFM), and body fat, in adolescent male ice hockey players remains unresolved in current literature. The aim of this study was to assess the relationship between agility and age in adolescent male ice hockey players.

\section{METHODS}

Every year, youth hockey players participate in a battery of hockey-related tests designed to assess players fitness and performance level. However, because of morphological and physiological changes during pubescence, not all the tests are considered as suitable performance predictors. Thus, the analyses of anthropometric and somatic profiles were conducted to assess the differences between male youth hockey players of different age groups. The agility performance was evaluated to indicate the differences between the age groups. Then, correlations were calculated 
to examine association between anthropometric and somatic variables and both off-ice agility tasks. These results showed influence of age and anthropometrical and somatic variables on agility performance in adolescent male ice hockey players.

\section{PARTICIPANTS}

A total of 60 young male hockey players (12.98 years, $162.62 \pm 11.84 \mathrm{~cm}, 54.85 \pm 14 \mathrm{~kg}$ ) were recruited from the same professional hockey 2 nd division team. Participants were divided into 5 groups according to age (11-15 years [11y, 12y, 13y, 14y, and 15y]).

All hockey players participated in the regular training sessions and scheduled matches of the competition in the whole season. The exclusion criteria were chronic ankle instability and any lower extremity musculoskeletal injuries in the previous 6 months. Parents of the participants signed a written informed consent before the start of the study. The study was approved by the Ethics Committee (no. 4/2018) of the Faculty of Physical Culture, Palacký University Olomouc, Czech Republic in accordance with the ethical standards of the Declaration of Helsinki.

\section{PROCEDURES}

Data collection was conducted at a local hockey stadium after the end of the regular ice hockey season. First, the body height of each participant, while being barefoot, was obtained. Further, body composition was measured using a bioelectrical impedance device. Second, each participant performed two trials of both agility tasks (i.e., T-Test and EDGREN). There was a 60-s rest period between each trial and 2-min rest period between each agility task. Participants were provided 10min dynamic warm-up, including jogging and stretching, and practice trials on both tasks before the start of actual testing. Each participant performed EDGREN first, followed by the T-Test.

\section{MEASURES}

Body height was measured using a stadiometer (Leicester High Measure MK II, Leicester, Great Britain). Total body weight, FFM, SMM, and body fat percentage (BF\%) were measured by the InBody230 bioelectrical impedance device (Biospace, Seoul, Korea) in the morning after overnight fasting and emptying the bladder. Measurements were obtained with all participants wearing light underwear. Then, agility performance level was evaluated by T-test (Pauole, Madole, Garhammer, Lacourse. \& Rozenek, 2000) and Edgren Side Step Test (EDGREN) (Farlinger, Kruisselbrink \& Fowles, 2007), both with good validity and reliability (Pauole et al., 2000; Raya et al., 2013).

\section{STATISTICAL ANALYSIS}

Data from this investigation were analysed using STATISTICA (version 13; TIBCO Software, CA, USA). Data were normally distributed, as evaluated by the Kolmogorov-Smirnov test. Oneway analysis of variance was used to investigate mean differences and partial eta-squared $\left(\eta^{2}\right)$ for the assessment of effect size. The effect was considered as small $\left(\eta^{2}=0.01-0.05\right)$, medium $\left(\eta^{2}=0.06-0.13\right)$, and large $\left(\eta^{2} \geq 0.14\right)$ (Miles \& Shevlin, 2001). Tukey's (HSD) post hoc test 
was used to investigate mean differences between groups. Significance level was set at $\alpha=0.05$. Pearson correlation coefficients were used to examine the relationship between agility tests and anthropometric variables as follows: small effect $r_{p}=0.10-0.29$, medium effect $r_{p}=0.30-0.49$, and large effect $r_{p} \geq 0.5$ (Dishman \& Buckworth, 1996). Further, for the selected variables (Height, Weight, SMM\%, FFM\% and BF\%), there was calculated an expression of $\%$ of the total variance $\left(r_{p}{ }^{2 *} 100\right)$ that explains the effect of the factor on the observed effect.

\section{RESULTS}

Considering all hockey players, we found significant differences between groups with various ages in all variables, except FFM\% and BF\% (Table 1). There were significant differences in SMM\% only between groups $11 \mathrm{y}$ and $14 \mathrm{y}(p=0.01)$ and $11 \mathrm{y}$ and $15 \mathrm{y}(p=0.01)$.

Table 1. Description of anthropometric, somatic, and agility variables for each group. Differences in selected variables among all groups

\begin{tabular}{|c|c|c|c|c|c|c|c|c|c|c|c|c|}
\hline \multirow[t]{2}{*}{ Parameter } & \multirow{2}{*}{\multicolumn{2}{|c|}{$\begin{array}{c}11 y \\
(n=13) \\
\text { Mean } \pm \text { SD }\end{array}$}} & \multirow{2}{*}{\multicolumn{2}{|c|}{$\begin{array}{c}12 y \\
(\mathbf{n}=11) \\
\text { Mean } \pm \text { SD }\end{array}$}} & \multirow{2}{*}{\multicolumn{2}{|c|}{$\begin{array}{c}13 y \\
(n=13) \\
\text { Mean } \pm \text { SD }\end{array}$}} & \multirow{2}{*}{\multicolumn{2}{|c|}{$\begin{array}{c}14 y \\
(n=10) \\
\text { Mean } \pm \text { SD }\end{array}$}} & \multirow{2}{*}{\multicolumn{2}{|c|}{$\begin{array}{c}15 y \\
(n=13) \\
\text { Mean } \pm S D\end{array}$}} & \multicolumn{2}{|c|}{$\begin{array}{l}\text { All groups } \\
(\mathbf{n}=60)\end{array}$} \\
\hline & & & & & & & & & & & P-value & $\eta^{2}$ \\
\hline Height & 149.00 & 4.85 & 158.65 & 9.71 & 160.89 & 8.21 & 173.13 & 7.39 & 173.25 & 6.74 & $<0.001$ & 0.63 \\
\hline Weight & 40.46 & 7.47 & 48.87 & 6.96 & 52.62 & 8.92 & 64.88 & 12.75 & 68.82 & 10.38 & $<0.001$ & 0.58 \\
\hline SMM\% & 42.83 & 2.82 & 44.09 & 4.06 & 44.91 & 2.18 & 47.63 & 2.26 & 46.80 & 2.98 & $<0.001$ & 0.28 \\
\hline FFM\% & 80.71 & 5.71 & 81.24 & 6.93 & 81.65 & 3.07 & 85.01 & 3.51 & 83.21 & 4.95 & 0.269 & 0.09 \\
\hline BF\% & 19.29 & 5.71 & 18.80 & 6.93 & 18.33 & 3.05 & 14.99 & 3.51 & 16.80 & 4.96 & 0.267 & 0.09 \\
\hline EDGREN & 25.46 & 0.78 & 27.00 & 3.85 & 28.85 & 3.91 & 28.30 & 2.21 & 28.92 & 2.33 & 0.015 & 0.20 \\
\hline T-Test & 14.38 & 0.90 & 13.86 & 0.99 & 13.26 & 0.97 & 11.92 & 0.73 & 11.54 & 0.95 & $<0.001$ & 0.61 \\
\hline
\end{tabular}

Height in cm; Weight in kg; SMM\%, skeletal muscle mass percentage; FFM\%, fat-free mass percentage; BF\%, body fat percentage, EDGREN, number of crossed cones; T-Test, duration of the test in seconds.

Agility testing, particularly in T-Test, revealed significant differences in all groups, except groups $11 \mathrm{y}$ and $12 \mathrm{y}(p=0.64), 12 \mathrm{y}$ and $13 \mathrm{y}(p=0.51), 14 \mathrm{y}$ and $15 \mathrm{y}(p=0.86)$. Significant differences were found in EDGREN only between groups 11y and 13y $(p=0.03)$ and $11 \mathrm{y}$ and $15 \mathrm{y}$ $(p=0.02)$.

Pearson correlations between agility tests and anthropometric and somatic variables are shown in Table 2. The largest correlations were found between T-test and height $\left(r_{p}=-0.68\right)$, T-test and weight $\left(r_{p}=-0.63\right)$, and T-test and SMM\% $\left(r_{p}=-0.61\right)$.

Table 2. Correlations $\left(r_{p}\right)$ between agility tests and monitored variables and expression of percentage of the total variance

\begin{tabular}{llccc}
\hline & \multicolumn{2}{c}{ EDGREN } & \multicolumn{3}{c}{ T-Test } \\
$\mathrm{N}=60$ & $\mathrm{r}_{\mathrm{p}}$ & $\%$ & $\mathrm{r}_{\mathrm{p}}$ & $\%$ \\
\hline Height & 0.4 & 16.11 & -0.68 & 45.72 \\
Weight & 0.38 & 14.3 & -0.63 & 40.3 \\
SMM\% & 0.42 & 17.67 & -0.61 & 37.14 \\
FFM\% & 0.29 & 8.28 & -0.4 & 15.89 \\
BF\% & -0.29 & 8.19 & 0.4 & 15.71 \\
\hline
\end{tabular}

$\%$, expression of $\%$ of the total variance that explains the effect of the factor on the observed effect; SMM\%, skeletal muscle mass percentage; FFM\%, fat-free mass percentage; $\mathrm{BF} \%$, body fat percentage 


\section{DISCUSSION}

In our study, we evaluated the influence of age and anthropometrical and somatic variables on agility performance in adolescent male ice hockey players. Moreover, we assessed the relationship between anthropometric and somatic variables (i.e., height, weight, SMM\%, FFM\%, and BF\%) and agility performance (T-Test and EDGREN).

Generally, it was shown that agility skills improved with age from childhood to adolescence and maturity (Zemková \& Hamar, 2012). We reported similar findings in adolescent male ice hockey players. Results showed differences in agility skills as older individuals had better results in both specific agility tasks than their younger peers. The highest differences were noted between players aged 14-15 years compared to younger ones, similarly as in the study evaluating the physical development of young Russian ice hockey players (Surina-Marysheva et al., 2018). Development of agility during childhood may lead to improvement in motor skills and object control skills in general. These specific skills have a strong influence on subsequent fitness in adolescence (Barnett, Van Beurden, Morgan, Brooks, \& Beard, 2008).

Results of the somatic variables revealed that SMM\%, FFM\%, and BF\% differ the most in players aged 13 to 14 years, where it is based on chronological age of the players, co there could be some differences in comparison of biological age. Similar findings were shown in a study describing the evolution of selected parameters (i.e., morphological, physiological) of high-level Canadian ice hockey players (aged $13.1 \pm 0.6$ years) in three sessions over 1 year (Allisse et al., 2017). The period between childhood and adolescence is an important lifetime period in which healthy weight gain can be promoted and fat gain can be reduced (Barbour-Tuck, Erlandson, Muhajarine, Foulds, \& Baxter-Jones, 2018). In this period, physical activity is a modifiable lifestyle factor capable of alleviating fat gain (Barbour-Tuck et al., 2018; Thompson, Karpe, Lafontan, \& Frayn, 2012). During physical maturity, men gain greater amounts of FFM and SMM (LoombaAlbrecht \& Styne, 2009). This factor is important especially in competitive sport disciplines. Early physical maturation of young hockey players increases their chance of being selected for the elite level of ice hockey in adolescence and adulthood (Roczniok et al., 2016; Sherar, Baxter-Jones, Faulkner, \& Russell, 2007).

Thus, the T-Test results showed that there were significant differences between all groups in favour of participants at least 2 years older, except for differences between groups 13y and 14y. EDGREN revealed significant differences only between groups $11 \mathrm{y}$ and $13 \mathrm{y}$ and $11 \mathrm{y}$ and $15 \mathrm{y}$. These results may be influenced by the differences in body composition and specificity of both tasks (Jones \& Lorenzo, 2013; Spasic, Uljevic, Coh, Dzelalija, \& Sekulic, 2013). The results obtained from agility tasks (Table 2 ) showed that, in young hockey players, T-Test is more related to anthropometric (Height, 45.72\%; Weight, 40.30\%) and somatic variables (SMM\%, 37.14\%; FFM\%, 15.89\%, BF\%, 15.71\%) than EDGREN (Height, 16.11\%; Weight, 14.30\%; SMM\%, 17.67\%; FFM\%, 8.28\%, BF\%, 8.19\%).

With respect to the results of our study, there is a correlation between anthropometric measures and specific change in direction speed (CODS) task performance. SMM\% seems to be the predictor of performance in specific CODS task in young and adolescent hockey players. Furthermore, comparing two players with equal anthropometric parameters but different SMM\%, the athlete with higher $\mathrm{BF} \%$ will have less lean mass to contribute to the speed requirements of agility performance (Sheppard et al., 2014). Lower SMM\% and higher BF\% would require greater force to produce a required change in velocity or direction (Enoka, 2002). Considering the body height, shorter athletes are capable of lowering the centre of mass to gain greater stability and perform quick and fast lateral cutting manoeuvres from sliding (Shimokochi, Ide, Kokubu, \& Nakaoji, 2013), which are essential in ice hockey. Lowering the body's centre of mass requires 
a specific technique and sufficient lower extremity muscle extensor power output capabilities, strength, and endurance (Shimokochi et al., 2013). Although performance in both agility tasks, where high-velocity lateral CODS is required, was better in taller athletes, this result is rather a confirmation that the decisive factor is the SMM and body fat mass of the athlete.

Considering the ice hockey, we recommend using the EDGREN to test children, in the age range from 11 years to early adolescence, as it is less related to body height, weight, and muscle growth, which is natural in this period of growth spurt (Philippaerts et al., 2006). T-Test, as it is related to body height, weight, and muscle growth, seems to be a better tool for testing agility in late adolescent and adult ice hockey players, where physical growth and maturation have been completed (Chulani and Gordon, 2014).

\section{CONCLUSION}

Therefore, the present results revealed that agility skills improve with age in adolescent male ice hockey players. Anthropometric variables differ the most between players aged 13 to 14 years. EDGREN was less related to body height, weight, and muscle growth and seems to be a better tool for testing agility skills in children from the end of the middle childhood to early adolescence. T-Test, as it is related to body height, weight, and muscle growth, should be used for testing agility in late adolescent and adult hockey players.

\section{References}

Allisse, M., Sercia, P., Comtois, A. S., \& Leone, M. (2017). Morphological, physiological and skating performance profiles of male age-group elite ice hockey players. Journal of Human Kinetics, 58(1), 87-97. https://doi.org/10.1515/ hukin-2017-0085

Artero, E. G., España-Romero, V., Ortega, F. B., Jiménez-Pavón, D., Ruiz, J. R., Vicente-Rodríguez, G., ... Castillo, M. J. (2010). Health-related fitness in adolescents: Underweight, and not only overweight, as an influencing factor. The AVENA study. Scandinavian Journal of Medicine and Science in Sports, 20(3), 418-427. https://doi.org/10.1111/j.1600-0838.2009.00959.x

Barbour-Tuck, E., Erlandson, M., Muhajarine, N., Foulds, H., \& Baxter-Jones, A. (2018). Influence of childhood and adolescent fat development on fat mass accrual during emerging adulthood: A 20-year longitudinal study. Obesity, 26(3), 613-620. https://doi.org/10.1002/oby.22111

Barnett, L. M., Van Beurden, E., Morgan, P. J., Brooks, L. O., \& Beard, J. R. (2008). Does childhood motor skill proficiency predict adolescent fitness? Medicine and Science in Sports and Exercise, 40(12), 2137-2144. https://doi.org/10.1249/ MSS.0b013e31818160d3

Behm, D. G., Wahl, M. J., Button, D. C., Power, K. E., \& Anderson, K. G. (2005). Relationship between hockey skating speed and selected performance measures. Journal of Strength and Conditioning Research, 19(2), 326-331. https://doi. org/10.1519/R-14043.1

Bracko, M. R., Fellingham, G. W., Hall, L. T., Fisher, A. G., \& Cryer, W. (1998). Performance skating characteristics of professional ice hockey forwards. Sports Medicine, Training and Rehabilitation, 8(3), 251-263. https://doi. org/10.1080/15438629809512531

Burr, J. F., Jamnik, R. K., Baker, J., Macpherson, A., Gledhill, N., \& McGuire, E. J. (2008). Relationship of physical fitness test results and hockey playing potential in elite-level ice hockey players. Journal of Strength \& Conditioning Research, 22(5), 1535-1543. https://doi.org/10.1519/JSC.0b013e318181ac20

Chelladurai, P. (1976). Manifestations of agility. Canadian Association of Health, Physical Education, and Recreation, 42(3), 36-41.

Chulani, V. L., \& Gordon, L. P. (2014). Adolescent growth and development. Primary Care Clinics in Office Practice, 41(3), 465-487. https://doi.org/10.1016/j.pop.2014.05.002

Dishman, R. K., \& Buckworth, J. (1996). Increasing physical activity: A quantitative synthesis. Medicine and Science in Sports and Exercise, 28(6), 706-719.

Enoka, R. M. (2002). Neuromechanics of Human Movement 3rd ed. In Neuromechanical Basis of Kinesiology. Champaign, Illinois: Human Kinetics.

Farlinger, C. M., Kruisselbrink, L. D., \& Fowles, J. R. (2007). Relationships to skating performance in competitive hockey players. The Journal of Strength and Conditioning Research, 21(3), 915-922. https://doi.org/10.1519/R-19155.1

Jeffreys, I. (2011). A task-based approach to developing context-specific agility. Strength and Conditioning Journal, 33(4), 52-59. https://doi.org/10.1519/SSC.0b013e318222932a 
Jones, M. T., \& Lorenzo, D. C. (2013). Assessment of power, speed, and agility in athletic, preadolescent youth. Journal of Sports Medicine and Physical Fitness, 53(6), 693-700.

Loomba-Albrecht, L. A., \& Styne, D. M. (2009). Effect of puberty on body composition. Current Opinion in Endocrinology, Diabetes and Obesity, 16(1), 10-15. https://doi.org/10.1097/MED.0b013e328320d54c

Miles, J., \& Shevlin, M. (2001). Applying regression \& correlation: A guide for students and researchers. London: Sage Publications.

Novák, D., Lipinska, P., Roczniok, R., Spieszny, M., \& Stastny, P. (2019). Off-ice agility provide motor transfer to on-ice skating performance and agility in adolescent ice hockey players. Journal of Sports Science \& Medicine, 18(4), 680-694. Retrieved from https://pubmed.ncbi.nlm.nih.gov/31827353

Paul, D. J., Gabbett, T. J., \& Nassis, G. P. (2016). Agility in team sports: Testing, training and factors affecting performance. Sports Medicine, 46(3), 421-442. https://doi.org/10.1007/s40279-015-0428-2

Pauole, K., Madole, K., Garhammer, J., Lacourse, M., \& Rozenek, R. (2000). Reliability and validity of the T-test as a measure of agility, leg power, and leg speed in college-aged men and women. The Journal of Strength and Conditioning Research, 14(4), 443-450. https://doi.org/10.1519/1533-4287(2000)014<0443:RAVOTT>2.0.CO;2

Philippaerts, R. M., Vaeyens, R., Janssens, M., Van Renterghem, B., Matthys, D., Craen, R., ... Malina, R. M. (2006). The relationship between peak height velocity and physical performance in youth soccer players. Journal of Sports Sciences, 24(3), 221-230. https://doi.org/10.1080/02640410500189371

Puciato, D., Mynarski, W., Rozpara, M., Borysiuk, Z., \& Szyguła, R. (2011). Motor development of children and adolescents aged 8-16 years in view of their somatic build and objective quality of life of their families. Journal of Human Kinetics, 28(1), 45-53. https://doi.org/10.2478/v10078-011-0021-1

Quinney, H. A., Dewart, R., Game, A., Snydmiller, G., Warburton, D., \& Bell, G. (2008). A 26 year physiological description of a National Hockey League team. Applied Physiology, Nutrition, and Metabolism, 33(4), 753-760. https://doi.org/10.1139/ H08-051

Raya, M. A., Gailey, R. S., Gaunaurd, I. A., Jayne, D. M., Campbell, S. M., Gagne, E., ... Tucker, C. (2013). Comparison of three agility tests with male servicemembers: Edgren Side Step Test, T-Test, and Illinois Agility Test. Journal of Rehabilitation Research and Development, 50(7), 951-960. https://doi.org/10.1682/JRRD.2012.05.0096

Roczniok, R., Stanula, A., Maszczyk, A., Mostowik, A., Kowalczyk, M., Fidos-Czuba, O., \& Zając, A. (2016). Physiological, physical and on-ice performance criteria for selection of elite ice hockey teams. Biology of Sport, 33(1), 43-48. https://doi. org/10.5604/20831862.1180175

Scanlon, A., Humphries, B., Tucker, P. S., \& Dalbo, V. (2014). The influence of physical and cognitive factors on reactive agility performance in men basketball players. Journal of Sports Sciences, 32(4), 367-374. https://doi.org/10.1080/02640 414.2013.825730

Sheppard, J. M., Dawes, J. J., Jeffreys, I., Spiteri, T., \& Nimphius, S. (2014). Broadening the view of agility: A scientific review of the literature. Journal of Australian Strength and Conditioning, 22(3), 6-24.

Sheppard, J. M., \& Young, W. B. (2006). Agility literature review: Classifications, training and testing. Journal of Sports Sciences, 24(9), 919-932. https://doi.org/10.1080/02640410500457109

Sherar, L. B., Baxter-Jones, A. D. G., Faulkner, R. a, \& Russell, K. W. (2007). Do physical maturity and birth date predict talent in male youth ice hockey players? Journal of Sports Sciences, 25(8), 879-886. https://doi.org/10.1080/02640410600908001

Shimokochi, Y., Ide, D., Kokubu, M., \& Nakaoji, T. (2013). Relationships among performance of lateral cutting maneuver from lateral sliding and hip extension and abduction motions, ground reaction force, and body center of mass height. Journal of Strength and Conditioning Research, 27(7), 1851-1860. https://doi.org/10.1519/JSC.0b013e3182764945

Sigmund, M., Kohn, S., \& Sigmundova, D. (2016). Assessment of basic physical parameters of current Canadian-American National Hockey League (NHL) ice hockey players. Acta Gymnica, 46(1), 30-36. https://doi.org/10.5507/ag.2015.027

Spasic, M., Uljevic, O., Coh, M., Dzelalija, M., \& Sekulic, D. (2013). Predictors of agility performance among early pubescent girls. International Journal of Performance Analysis in Sport, 13(2), 480-499. https://doi.org/10.1080/24748668.2013.1 1868664

Surina-Marysheva, E. F., Erlikh, V. V., Korableva, Y. B., Kantyukov, S. A., \& Ermolaeva, E. N. (2018). Physical development of hockey players aged 13-16 years. Pedagogics, Psychology, Medical-Biological Problems of Physical Training and Sports, 22(2), 107. https://doi.org/10.15561/18189172.2018.0207

Thompson, D., Karpe, F., Lafontan, M., \& Frayn, K. (2012). Physical activity and exercise in the regulation of human adipose tissue physiology. Physiological Reviews, 92(1), 157-191. https://doi.org/10.1152/physrev.00012.2011

Young, W. B., Dawson, B., \& Henry, G. J. (2015). Agility and change-of-direction speed are independent skills: Implications for training for agility in invasion sports. International Journal of Sports Science and Coaching, 10(1), 159-169. https:// doi.org/10.1260/1747-9541.10.1.159

Young, W. B., James, R., \& Montgomery, I. (2002). Is muscle power related to running speed with changed of direction? Journal of Sports Medicine and Physical Fitness, 42(3), 282-288.

Young, W., \& Rogers, N. (2014). Effects of small-sided game and change-of-direction training on reactive agility and changeof-direction speed. Journal of Sports Sciences, 32(4), 307-314. https://doi.org/10.1080/02640414.2013.823230

Zemková, E., \& Hamar, D. (2012). Age-related changes in agility time in children and adolescents. International Journal of Science and Research, 3(11), 2319-7064.

Zemková, E., \& Hamar, D. (2014). Agility performance in athletes of different sport specializations. Acta Universitatis Palackianae Olomucensis, Gymnica, 44(3), 133-140. https://doi.org/10.5507/ag.2014.013 